$\begin{array}{lcl}\text { Tükiye Tarımsal Araştırmalar Dergisi } & \text { Turk J Agric Res } \\ \text { 2018, 5(2): 176-182 } & \text { (TÜTAD } \\ \text { dergipark.gov.tr/tutad } & \text { ISSN: 2148-2306 } \\ \text { e-ISSN: 2528-858X } & \text { doi: 10.19159/tutad.392683 }\end{array}$

\title{
Bitkilerde Sinyal Molekülü Hidrojen Sülfür $\left(\mathrm{H}_{2} \mathrm{~S}\right)$
}

\author{
İlkay YAVAŞ ${ }^{*}$, Aydın ÜNAY ${ }^{2}$ \\ ${ }^{1}$ Adnan Menderes Üniversitesi, Koçarl Meslek Yüksekokulu, Bitkisel ve Hayvansal Üretim Bölümü, Aydın, TÜRKIYE \\ ${ }^{2}$ Adnan Menderes Üniversitesi, Ziraat Fakültesi, Tarla Bitkileri Bölümü, Aydın, TÜRKIYYE
}

\begin{tabular}{ll}
\hline \multicolumn{1}{c}{ Geliş Tarihi/Received: 09.02 .2018} & Kabul Tarihi/Accepted: 13.06 .2018 \\
\hline ORCID IID (Yazar sirasına göre / by author order) \\
(1Dorcid.org/0000-0002-6863-9631 (Dorcid.org/0000-0002-7278-4428 \\
"Sorumlu Yazar/Corresponding Author: iyavas@adu.edu.tr
\end{tabular}

Özet: Hidrojen sülfür $\left(\mathrm{H}_{2} \mathrm{~S}\right)$ renksiz oluşu ve çürük yumurta kokusu ile yıllardır toksik olarak bilinen bir gazdır. Hidrojen sülfürün bitki hücreleri üzerindeki etkisi yüksek konsantrasyonda olmasına bağlı olarak diğer çevresel stres koşulları ile birleştiğinde bitki için fitotoksik hale gelmektedir. Hidrojen sülfürün bitkilerde stoma hareketleri, çiçeklerde ve yapraklarda yaşl1lığın düzenlenmesi, fotosentez ve çimlenme gibi çeşitli fizyolojik olaylar üzerine önemli etkisi bulunmaktadır. Ağır metal içeriği, kuraklık, su taşkını, tuz, mantari enfeksiyonlar, UV-B artışı, soğuk ve sıcak stresi gibi çeşitli abiyotik stres koşulları $\mathrm{H}_{2} \mathrm{~S}$ 'ün içsel sentezini tetiklemektedir. Bitkiler çevresel streslere tepki olarak hidrojen sülfürü L-sistein desülfidraz (LCD), D-sistein desülfidraz (DCD), sülfat redüktaz (SİR), siyanoalanin sentez (CAS) ve sistein sentezi (CS) yoluyla sentezlemektedir ve bu stres koşullarına karşı bitkinin toleransını artırmaktadır. Bitkiler tarafından üretilen hidrojen sülfürün fazlası da atmosfere verilmektedir. Bu nedenle, $\mathrm{H}_{2} \mathrm{~S}^{\prime}$ ü bir fitotoksin olmasının yanı sıra sinyal molekülü olarak ta düşünmek gerekmektedir.

Anahtar Kelimeler: Abiyotik stres, bitkiler, hidrojen sülfür, sinyal molekülü, sistein

\section{Signal Molecule Hydrogen Sulfide $\left(\mathrm{H}_{2} \mathrm{~S}\right)$ in Plants}

\begin{abstract}
Hydrogen sulfide $\left(\mathrm{H}_{2} \mathrm{~S}\right)$ is a gas known as toxic for years with the colorless formation and rotten egg odor. Hydrogen sulfide becomes phytotoxic for the plant when combined with other environmental stress conditions due to the high concentration of the effect on plant cells. Hydrogen sulfide plays a vital role in regulating various physiological processes such as stoma movements in plants, regulation of senescence in flowers and leaves, photosynthesis and germination. Various abiotic stress conditions such as heavy metal stress, drought, waterlogging, salinity, fungal infection, UV-B stress, cold and heat stress triggers the production of $\mathrm{H}_{2} \mathrm{~S}$. In response to environmental stresses, plants synthesize hydrogen sulfide via L-cysteine desulfhydrase (LCD), D-cysteine desulfhydrase (DCD), sulfate reductase (SIR), cyanoalanine synthesis (CAS) and cysteine synthesis (CS) and increase plant tolerance against these stress. Hydrogen sulfide produced by plants is also released to the atmosphere. For this reason, it is necessary to consider $\mathrm{H}_{2} \mathrm{~S}$ as a signal molecule as well as a phytotoxin.
\end{abstract}

Keywords: Abiotic stress, plants, hydrogen sulfide, signal molecule, cysteine

\section{Giriş}

Atmosferik karbondioksiti kullanarak organik bileşiklere dönüşümünü sağlayan bitkiler, atmosferdeki değişimlerden önemli ölçüde etkilenirler. Yaklaşık 200 y1l önce sanayi devriminin başlaması ile birlikte $\mathrm{CO}_{2}$ içeriğ 270 $\mu \mathrm{L} \mathrm{L} \mathrm{L}^{-1}$ 'den $401 \mu \mathrm{L} \mathrm{L} \mathrm{L}^{-1}$ 'e yükselmiş, ortalama sıcaklıklar $0.85{ }^{\circ} \mathrm{C}$ artmıștır. Bu yüzyılın sonunda sera gazı senaryolarına göre, karbondioksitin en az $700 \mu \mathrm{L} \mathrm{L}^{-1}$ 'e ulaşması ve sicaklıkların $4{ }^{\circ} \mathrm{C}$ veya daha fazla yükselmesi beklenmektedir. (Anonymous, 2013). Hızlı iklim değişiklikleri 
nedeniyle bitkiler yeni çevre koşullarına giderek daha fazla maruz kalmaktadırlar (Becklin ve ark., 2016).

Enerji elde etmek için jeotermal sistemler önemli kaynaklardır. Jeotermal atıklar yeryüzüne ulaştığında düşük basınç ve sıcaklığın etkisi ile gazlar sıvidan ayrilmakta ve $\mathrm{CO}_{2}$ ile bir miktar hidrojen sülfür $\left(\mathrm{H}_{2} \mathrm{~S}\right)$ açığa çıkmaktadır (Şekil 1). Ayrıca düşük miktarlarda hidrojen, metan, kükürt dioksit, amonyak ve nitrojen gazları ile çok düşük miktarlarda metal buharları da ortaya çıkmaktadır (Çengel, 2015). Oysa içsel olarak $\mathrm{H}_{2} \mathrm{~S}$ 'ün bakteriler, mantarlar, solucanlar, insanlar ve bitkiler gibi çeşitli organizmalarda gaz halinde sinyal molekülü olarak hızla ortaya çıktığ1 saptanmıştır (Pandey, 2014). Önceki çalışmalarda $\mathrm{H}_{2} \mathrm{~S}$ bitki büyüme ve gelişimi üzerinde zararlı etkilere sahip olan bir fitotoksin olarak yer almaktadır. Günümüzde bitkilerin sistein desulfhidraz üreten enzimlere sahip olduğu ve O-asetilserin liyazı uzaklaştırdığı bilinmektedir. Hidrojen sülfürün bitki fizyolojisi ve hastalıklara dayanıklılık gibi bitkiler üzerindeki etkileri 1960'lardan beri bilinmektedir. Bir sinyal molekülü olan $\mathrm{H}_{2} \mathrm{~S}$ 'ün, son yıllarda yapılan birçok çalışmada bekçi hücreler üzerinde de etkili olduğu bildirilmiştir (Pandey, 2014).

Hayvanlar üzerinde yapılan çalışma, $\mathrm{H}_{2} \mathrm{~S}$ 'ün, sistein gruplarının tiol modifikasyonları üzerinde doğrudan etkili olduğunu, bunun bitkiler üzerinde gerçekleştirilecek çalışmalar için bir ön bilgi oluşturacağ1 düşünülmektedir. $\mathrm{Bu}$ nedenle, $\mathrm{H}_{2} \mathrm{~S}$ ’ü fitotoksin olarak düşünmek yerine, reaktif oksijen türleri ve nitrik oksit metabolizmasıyla etkileşime giren ve proteinlerin aktivitesi üzerinde doğrudan etkiye sahip bir sinyal molekülü olarak düşünmek gerekmektedir (Lisjak ve ark., 2013).

Özellikle jeotermal kaynaklardan enerji elde edilmesi esnasinda atmosfere verilen baca gazlarının bileşiminde yer alan $\mathrm{H}_{2} \mathrm{~S}$ güncelliğini artırmaktadır. Hidrojen sülfürün dışa salınımı dışında, bitkiler içerisinde içsel olarak üretilmesi ve fizyolojik fonksiyonları dikkati çekmektedir. $\mathrm{Bu}$ derlemede, $\mathrm{H}_{2} \mathrm{~S}$ 'ün bitkiler üzerindeki olas1 etkileri incelenmiş ve fizyolojik fonksiyonları üzerinden yapılan çalışmalar değerlendirilmiştir.

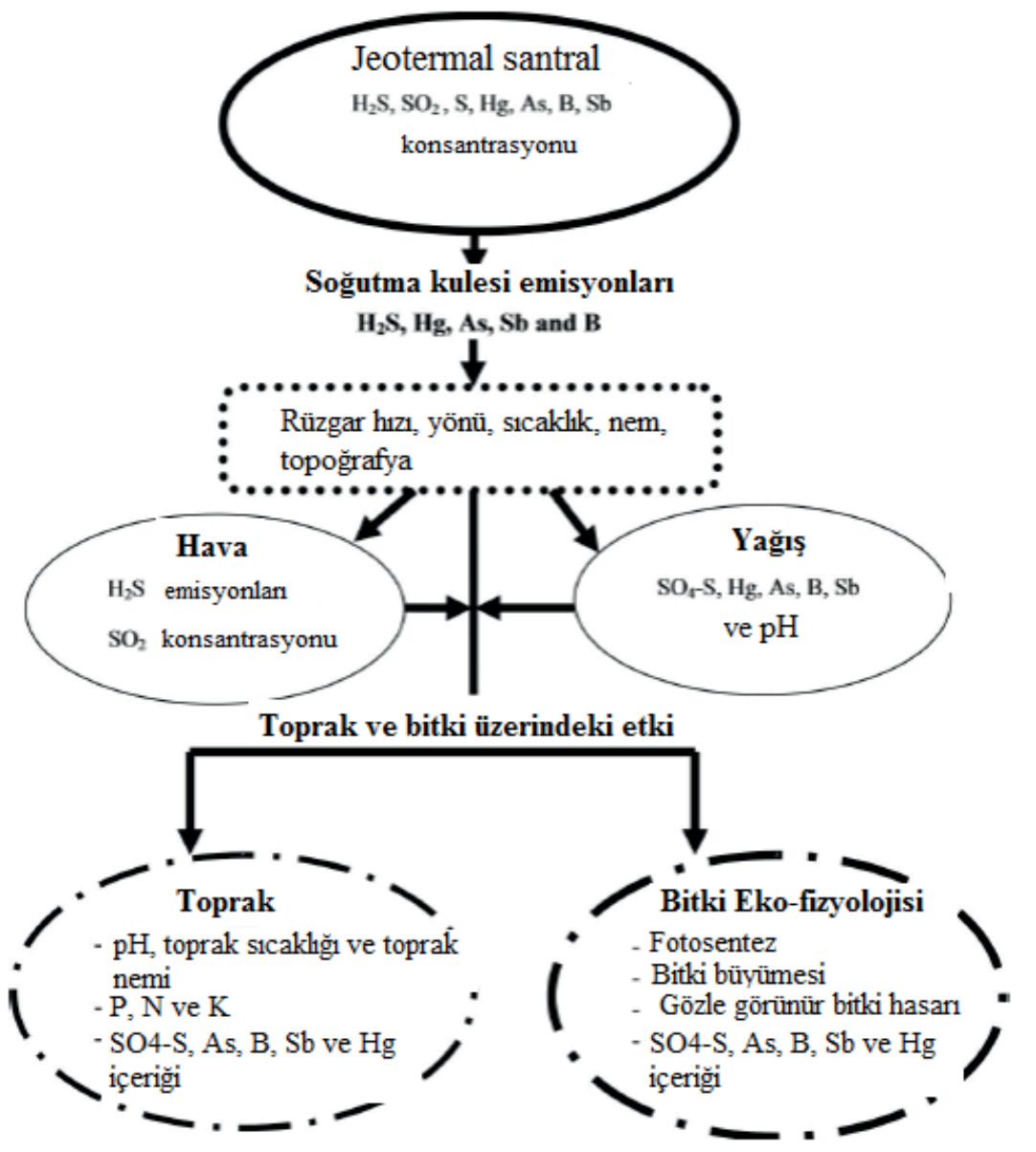

Şekil 1. Jeotermal tesislerden salınan gazların toprak ve bitki üzerine etkileri (Mutia ve ark., 2013'den değiştirilerek) 


\section{Hidrojen Sülfürün Bitkiler Üzerindeki Etkisi}

Atmosferdeki $\mathrm{H}_{2} \mathrm{~S}$ 'ün mısır, balkabağı ve 1 spanak da dâhil olmak üzere birçok bitki üzerinde etkisi üzerine yürütülen çalışmalar transpirasyonu değiştirebileceğini, kısa vadede ise hiçbir etki yaratmayacağını göstermiştir. Bazı araştırıcılar, düşük düzeyde fümigasyonun (yaklaşık $100 \mathrm{ppb}$ ) yonca, marul ve şeker pancarı büyümesinde önemli bir artışa neden olduğunu bildirmiştir. Fakat şeker pancarında şeker oranını azalttığ1 ortaya çıkmıştır. Hidrojen sülfürün, NO sinyalini, farklı koşullar altında azaltarak ya da artırarak etkileșime girmesi gerçekten de bir fitotoksin gibi değil, aynı zamanda bir sinyal molekülü olarak hareket ettiğini akla getirmektedir.

Hidrojen sülfürün bitki hücreleri üzerinde bir etkisinin olması yüksek konsantrasyonda olmasına bağlıdır. Yüksek konsantrasyonlarda $\mathrm{H}_{2} \mathrm{~S}$ özellikle yüksek sıcaklık veya tuzluluk gibi stres koşulları ile bir araya geldiğinde zararlı etkileri nedeniyle fitotoksik hale gelmektedir. Yonca, marul, üzüm, şeker pancarı, çam ve köknar bitkilerinde 3000 ppb $\mathrm{H}_{2} \mathrm{~S}$ 'ün yapraklarda lezyonlara, yaprak dökülmesine ve bitkilerin büyümesinin azalmasına neden olduğu saptanmıştır. Bazı çalışmalar $\mathrm{H}_{2} \mathrm{~S}$ ’ün çeltik fidelerinde oksijen salınımını engellediğini göstermiştir. Ayrıca bazı çeltik çeşitlerinde de besin maddesi alımının azaldığı bildirilmiştir. Bununla birlikte, bazı çeşitlerde de besin maddesi alımının arttığı ve $\mathrm{H}_{2} \mathrm{~S}$ 'ün olumlu bir rol oynadığ gözlenmiştir (Lisjak ve ark., 2013).

Atmosferde $\operatorname{artan} \mathrm{H}_{2} \mathrm{~S}$ konsantrasyonları bitkilerde tiol metabolizması üzerinde belirgin bir etki yaratmakta ve kısa bir süre içerisinde (3-48 saat) $\mathrm{H}_{2} \mathrm{~S}$ 'e maruz kalma (0.25-0.75 $\left.\mathrm{ml} \mathrm{l}^{-1}\right)$ Arabidopsis thaliana'da sistein içeriğini 20 kat ve glutatyon içeriğini ise 4 kat artırmaktadır (Wang, 2012). Glutatyon kükürt yönünden zengin bir bileşik olup, $\mathrm{H}_{2} \mathrm{~S}$ metabolizmasıyla ilişkilidir. Hidrojen sülfür oksidatif stres tepkileri üzerine de etkili olabilmektedir. De Kok ve ark. (1985) yapraklardaki $\mathrm{H}_{2} \mathrm{~S}$ 'ün yaklaşık \% $\quad 40$ 'ının glutatyona dönüştüğünü vurgulamıştır. Atmosferde bulunan $\mathrm{H}_{2} \mathrm{~S}$ 'e kısa süreli maruz kalmanın, Brassica oleracea L.'nın sürgünlerinde yüksek oranda adrenosin 5'-fosfosfat redüktazın (APR) engellenmesine neden olduğu saptanmıştır. Adenozin Trifosfat-Sülfüraz (ATPS), serin asetil transferaz (SAT) ve O-asetilserin (tiyol) liyaz (OAS-TL) $\mathrm{H}_{2} \mathrm{~S}$ uygulamasından etkilenmemiş olup, tam tersine bu bitkilerin sürgünlerinde tiol içeriği artış göstermiştir. Sistein amino asitinin artışı tiol artışı ile birlikte $\mathrm{H}_{2} \mathrm{~S}$ 'e 5 gün maruz bırakılma sonucu üç kat daha artmıştır. Atmosferde bulunan $\mathrm{H}_{2} \mathrm{~S}$ 'e 48 saate kadar maruz kalma, hem sistein hem de glutatyonda önemli artışa neden olmuştur. Düşük $\mathrm{H}_{2} \mathrm{~S}$ seviyelerinin ( $\left.0.5 \mu 1 \mathrm{~L}^{-1} \mathrm{kadar}\right)$, haberci RNA'nın indüksiyonuna neden olduğu ve bu gibi enzimlerin daha yüksek protein seviyelerine sahip olduğu, yüksek konsantrasyonlarda $\left(0.75 \mu \mathrm{L} \mathrm{L}^{-1}\right) \mathrm{H}_{2}$ S'ün ters etkisi olduğu gözlenmiştir. Ayrıca alkol dehidrogenaz enziminin kökte toplam adenin nükleotitlerinin azalması, yaprak büyümesi ve azot alımındaki düşüş ile birlikte bitki hücrelerinde $\mathrm{H}_{2} \mathrm{~S}$ '̈̈ engellediği vurgulanmıştır. $\mathrm{H}_{2} \mathrm{~S}$ 'den etkilenen diğer enzimler arasında heme oksijenaz ${ }^{-1}\left(\mathrm{HO}^{-1}\right)$ yer almaktadır (Lisjak ve ark., 2013). Sülfit redüktazın koruyucu etkisini kavramak, endojen kükürt içeren savunma bileşiklerinin (SDC'ler) rolünün tam olarak anlaşılması açısından yararlı olacaktır. SDC'ler; glukozinolatlar, fitoaleksinler, elemental kükürt, glutatyon, hipotellinler, çeşitli ikincil metabolitler ve sülfür açısından zengin proteinleri kapsamaktadır. SDC'lerin biyotik ve abiyotik stres altında bitkilerin canlılıklarını sürdürmelerinde önemli payları bulunmaktadır (Wang, 2012).

Hidrojen sülfürün bitkilerdeki çeşitli fizyolojik süreçlerde önemli rol oynadığı gözlenmiştir. Yaşlı bitkilerin yaprakları, genç bitkilerden daha yüksek $\mathrm{H}_{2} \mathrm{~S}$ konsantrasyonları içermiştir. Bu nedenle bitki büyümesi, gelişimi ve yaşlanmasında $\mathrm{H}_{2} \mathrm{~S}$ 'ün önemi ortaya çıkmıştır. Dışarıdan yapılan $\mathrm{H}_{2} \mathrm{~S}$ uygulamalarına bağlı olarak tohum çimlenme hızlarında artış meydana gelmiştir (Jin ve Pei, 2015).

Hidrojen sülfürün etkisini belirlemek için yapılan çalışmalarda, sodyum hidrosülfit (NaHS) kullanılmakta, bu anlamda sodyum hidrosülfitin tohum çimlenmesinin teşvik edilmesinde önemli katkıları olduğu ortaya çıkmıştır. Sodyum hidrosülfit, endosperm $\beta$-amilaz aktivitesini etkilemiş ve çimlenen tohumlarda düşük malondialdehit ve hidrojen peroksit $\left(\mathrm{H}_{2} \mathrm{O}_{2}\right)$ düzeyleri gözlenmiştir. Ayrıca tatlı patates fidelerinde NaHS uygulamasının, adventif köklerin sayısını ve uzunluğunu arttırdı ğı belirlenmiştir. Hidrojen sülfür fotosentezle ilişkili genlerin ekspresyonunu ve tiyol redoks modifikasyonunu da düzenlemektedir. Stoma yoğunluğundaki artışın da bu sürece katkıda bulunduğu düşünülmektedir. Klorofil içeriğindeki ozmotik kaynaklı azalma, NaHS uygulaması ile azalmıştır. Hidrojen sülfürün, ayrıca kesilen çiçek ve dallarda doza bağlı olarak, çiçek açma ve yaşlanmayı geciktirdiği de saptanmıştır.

Hidrojen sülfür bitki metabolizmasını önemli derecede etkilemekte yüksek meyve verimleri de dâhil olmak üzere, biyomas üretiminde istatistiksel olarak önemli artışlara neden olmuştur. Hidrojen 
sülfürün önemli bir hücresel sinyal ve $\mathrm{H}_{2} \mathrm{~S}$ 'ün bakır $(\mathrm{Cu})$ stresine karşı koruyucu etkisinin olduğu ilk kez 2008 yılında ortaya çıkmıştır (Zhang ve ark., 2008). Ayrıca $\mathrm{H}_{2} \mathrm{~S}$ 'ün alüminyum, kadmiyum (Cd), krom ve bor toksisitesi, kuraklık ve ozmotik stres, sıcak stresi, hipoksi ve diğer stres etkilerini hafiflettiği gözlenmiştir. Kuraklık stresi altında, bitkilerden elde edilen $\mathrm{H}_{2} \mathrm{~S}$ üretim oranı artmıştır. A. thaliana'daki kuraklık stresinden sorumlu stoma regülasyonunda $\mathrm{H}_{2} \mathrm{~S}^{\prime}$ 'ün absisik asit ile etkileşime girdiği ortaya konmuştur. Hidrojen sülfür sinyali iletim aşamasında, gibberellik asit (GA) ve jasmonik asit (JA) ile ilişkilidir. Ayrıca $\mathrm{H}_{2} \mathrm{~S}$, buğday aleuron hücrelerinde GA ile indüklenen programlanmış hücre ölümünü hafifletebilir. Hidrojen sülfür, hidrojen peroksit $\left(\mathrm{H}_{2} \mathrm{O}_{2}\right)$ tarafindan aktive edilen plazma membranı kadmiyum kanallarının akışını engellemektedir. Hidrojen sülfür ağır metal stresi, ozmotik stres, sicaklık stresi ve hipoksi durumunda antioksidan sistemlerin geliştirilmesi yoluyla abiyotik strese bitki dayanıklılığının arttırılmasında da etkilidir (Li ve ark., 2016a; Da Silva ve Modolo, 2018). Hidrojen sülfür, nitrik oksit ve karbon monoksit sinyal yolunda da rol oynamıştır. Bermuda çiminde sodyum nitroprussidinin (SNP, NO verici) NaHS birlikte uygulanmasının, $\mathrm{NO}$ sinyalinin $\mathrm{H}_{2} \mathrm{~S}$ inhibitörleri ve temizleyiciler tarafından bloke edilebileceğini göstermiş ve bu da kadmiyum stresine tepki için $\mathrm{NO}$ ile aktive olan $\mathrm{H}_{2} \mathrm{~S}$ 'ün gerekli olduğunu ortaya koymuştur (Shi ve ark., 2013). Hidrojen sülfür ile uyarılan adventif kök oluşumunun büyük olasılıkla indol asetik asit ve nitrik oksit kaynaklı olduğu bulunmuştur (Zhang ve ark., 2009a). Ayrıca, $\mathrm{H}_{2} \mathrm{~S}$ 'ün kalsiyum (Ca) ile etkileşime girdiği ortaya konmmuştur. Kalsiyum, hücre duvarı yapısı ve dayanıklılığını sağlamakta ve kalmodulin yoluyla bitki gelişimini düzenlemektedir. Hidrojen sülfür, aluminyum toksisitesi ve sıcaklık stresine karşı prolin içeriğini arttırarak bitkileri koruma konusunda iyileştirici bir rol oynamaktadır. Alüminyum kaynaklı sitrat salınımı, NaHS ön-muamelesiyle de arttırılmıştır. NaHS ön inkübasyon periyodu sirasında $\beta$-amilaz etkinliğini artırarak tohum çimlenmesini olumlu yönde etkilediği gözlenmiştir (Jin ve Pei, 2015).

Ağır metaller arasında kurşun $(\mathrm{Pb})$, toprakta biriken potansiyel bir kirletici olup bitkilerdeki fizyolojik oluşumları olumsuz yönde etkilemektedir. Kurşun stresi koşullarında pamukta $\mathrm{H}_{2} \mathrm{~S}$ 'ün bitkinin hayatta kalmasında teşvik edici rolünün olduğu ortaya konmuştur (Bharwana ve ark., 2014). Atmosfere salınan $0.03 \mu \mathrm{L} \mathrm{L}^{-1}$ ya da daha yüksek seviyedeki $\mathrm{H}_{2} \mathrm{~S}^{\prime}$ 'ün toksik olduğu vurgulanmıştır. Fakat $\mathrm{H}_{2} \mathrm{~S}$ 'ün, özellikle sülfat $\left(\mathrm{SO}_{4}^{-2}\right)$ eksikliği ve köklere sınırlı miktarda sağlanması durumunda bitki büyümesi için bitki sürgünlerine sülfür (S) kaynağı olarak verildiğinde yararlı olduğu kanıtlanmıştır.

Zhang ve ark. (2009b) tatlı patateslerde sodyum sülfidratın (NaSH) ozmotik kaynaklı klorofil konsantrasyonlarındaki azalmay1 hafiflettiğini ortaya koymuşlardır. Sodyum sülfidratın uygulamasının süperoksit dismütaz, katalaz ve askorbat peroksidaz gibi antioksidan enzim aktivitelerini artırdığını, hidrojen peroksit ve lipoksigenaz içeriğini azalttığını bildirmişlerdir. $\mathrm{Bu}$ nedenle $\mathrm{H}_{2} \mathrm{~S}$ 'ün bitkilerde oksidatif strese karşı korumada rolü olabileceği ortaya çıkmıştır.

Hidrojen sülfür alımı büyük ölçüde, sürgünün iç kısmının (mezofil) $\mathrm{H}_{2} \mathrm{~S}$ 'e dayanıklılığ 1 ile belirlenmekte ve absorbe edilen sülfidin metabolizma oranını yansıtmaktadır. Krom stresi altında, $\mathrm{H}_{2} \mathrm{~S}$ 'ün etkisi buğday tohumunun çimlenmesini azaltmakta, ancak çimlenmedeki bu düşüş, $\mathrm{H}_{2} \mathrm{~S}$ donörü olarak NaHS'in ön işleme tabi tutulmasına bağlı olmaktadır. Hidrojen sülfürün $\mathrm{Cu}$ stresinin olumsuz etkisini hafiflettiği ve bitkileri oksidatif stresten korumada önemli bir rol oynadığ1 gözlenmiştir. Kurşun stresi pamuk bitkilerinin fizyolojik ve biyokimyasal işlevlerini olumsuz yönde etkilemektedir. Kurşun seviyesi arttıkça zarar daha da artmaktadır. Pamuk bitkisine dışarıdan $\mathrm{H}_{2} \mathrm{~S}$ uygulamasının, $\mathrm{Pb}$ stresinin zararlı etkisini ortadan kaldırma potansiyeline sahip olduğu ortaya çıkmıştır. Hidrojen sülfür ilavesi; büyüme parametreleri, biyomas, fotosentez, klorofil içerikleri, antioksidan aktivitelerini [süperoksit dismütaz (SOD), peoksidaz (POD), askorbat peroksidaz (APX) ve katalaz (CAT)] teşvik etmiş, pamuk bitkisinde $\mathrm{H}_{2} \mathrm{O}_{2}$, malondialdehit ve kurşun birikimini azaltmıştır (Bharwana ve ark., 2014).

\section{Bitkilerde Hidrojen Sülfür Üretimi}

Hidrojen sülfür, kükürt dioksit $\left(\mathrm{SO}_{2}\right)$ ile fümige olmuş yapraklardan açığa çıkan indirgenmiş bir sülfür bileşiğidir (Hällgren ve Fredriksson, 1982) ve atık arıtma tesislerinden, birçok tarımsal faaliyetlerden ve jeotermal kaynaklardan salınmaktadır (Lisjak ve ark., 2013). Ayrıca yoğun kükürt içeriği olan topraklarda bitkiler çevreye $\mathrm{H}_{2} \mathrm{~S}$ vermektedirler (Bharwana ve ark., 2014). Ayrica bitkilerin $\mathrm{SO}_{4}^{-2}$ veya $\mathrm{SO}_{2}$ 'ye maruz kaldığında çevreye $\mathrm{H}_{2} \mathrm{~S}$ yaydığ 1 da vurgulamıştır (Sekiya ve ark., 1982). Bitkiler almış oldukları sülfat ve sülfiti sülfür şeklinde yapraklardan dişarıya vermektedirler (Hällgren ve Fredriksson, 1982). Hidrojen sülfür, hasat sonrası bitkilerin bozulmadan kalmasını sağlamak ya da arazideki bitkilerin fizyolojisini iyileştirmek için kullanılabilir. Son çalışmalar $\mathrm{H}_{2} \mathrm{~S}$ 'ün bitkiler tarafından üretilen temel bir molekül olduğunu ve 
bitki fonksiyonunu kontrol etmek için kullanıldığını göstermiştir (Zhang ve ark., 2010; Lisjak ve ark., 2013; Jin ve Pei, 2015). Hidrojen sülfürün bitkiler tarafından üretimi çoğunlukla sistein metabolizmasından kaynaklanmaktadır. Sistein sentezleyen ve parçalayan enzimler örneğin O-asetil-L-serin (tiyol) liyaz (OAS-TL), L-sistein desülfhidraz (L-CD) ve merkaptopiruvat sülfürtransferaz bitkilerde $\mathrm{H}_{2} \mathrm{~S}$ üretimi ile yakından ilişkilidir. O-asetil-L-serin (tiyol) liyaz, O-asetil-Lserin ve sülfürden sistein oluşumunu katalize etmekte ve aynı zamanda sistein sentazı olarak da adlandırılmaktadır. İşlem sırasında $\mathrm{H}_{2} \mathrm{~S}$ bir yan reaksiyon olarak serbest birakilabilmektedir. L-sistein desulfhidraz (L-CD) ilk olarak 1980 yılında ortaya konmuştur. $\mathrm{H}_{2} \mathrm{~S}$, piruvat ve amonyum üretmek üzere L-sistein desülfhidraz, özellikle metabolize edilmektedir. Bu nedenle, bu enzim bir bitki savunma reaksiyonu sırasında $\mathrm{H}_{2} \mathrm{~S}$ salınmasında önemli bir faktör olarak karşımıza çıkmaktadır (Wang, 2012).
Salatalık, bal kabağı, soya fasulyesi ve pamuk gibi bazı bitkiler $\mathrm{H}_{2} \mathrm{~S}$ ve uçucu kükürt bileşikler üretmektedir. $\mathrm{Bu}$ durum 1şığa bağımlı olarak gerçekleşmektedir. Hidrojen sülfür uzun yıllardır toksik olduğu düşünülen bir gazdır. Bitki köklerine sülfat verildiği zaman 1 șık varlığında bitkiler bu emisyonlarını birkaç saat daha sürdürebilmektedirler. Ayrıca genç salatalık yapraklarının olgun yapraklara nazaran daha fazla $\mathrm{H}_{2} \mathrm{~S}$ saldığı ortaya çıkmıştır (Lisjak ve ark., 2013).

Hidrojen sülfür, bitkilerde hem enzimatik hem de enzimatik olmayan yollarla üretilmektedir. Fakat enzimatik olmayan yollarla üretim $\mathrm{H}_{2} \mathrm{~S}$ üretiminin sadece küçük bir bölümünü oluşturmaktadır. Şekil 2'de Arabidopsis thaliana bitkisinde $\mathrm{H}_{2} \mathrm{~S}$ üretimi gözlenmiştir. Sülfit redüktaz (SIR)'ın dışında $\mathrm{H}_{2} \mathrm{~S}$ üretimi yapabilen en az 4 enzim bulunmaktadır (Şekil 2). O-asetil-Lserin (tiyol) liyaz, OAS'den sistein sentezlemektedir. Bunların dișında sistein desülfidraz (DES1), siyanoalanin sentaz (CAS),

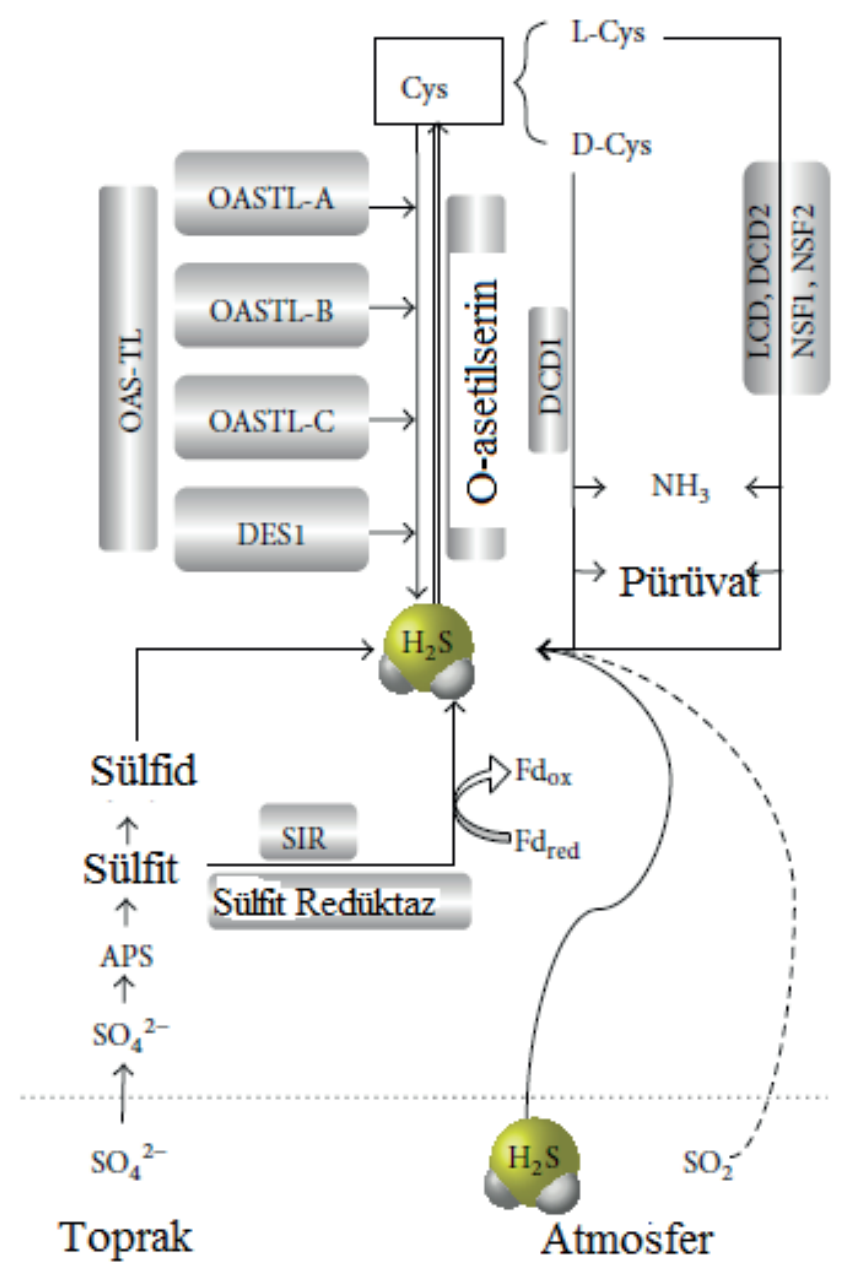

Şekil 2. Arabidopsis thaliana'da $\mathrm{H}_{2} \mathrm{~S}$ üretimi. APS: adenozin 5'-fosfosülfat; $\mathrm{Fd}_{\mathrm{red}}$, $\mathrm{Fd}$ : indirgenmiş ve oksidize olmuş ferrodoksin; SİR: sülfit redüktaz (Calderwood ve Kopriva (2014)'den değiştirilerek) 
D-sistein desülfidraz (DCD) yer almaktadır. Arabidopsis thaliana' da $\mathrm{H}_{2} \mathrm{~S}$ üreten enzimler iki kısma ayrilmaktadır. Birincisi, Cys desulfhidrazları (CDes'ler) olup Cys 1: 1: 1 oranında $\mathrm{H}_{2} \mathrm{~S}$, amonyak ve piruvata dönüştürülür ve bir kofaktör olarak piridoksal 5-fosfat gerektirmektedir. L-sistein desülfidraz, L-sistein'i ayrıştıran enzimlerden birisi olup, ilk olarak tütün hücrelerinin kükürt metabolizmasında keşfedilmiştir. CDes'lerin mRNA seviyeleri, A. thaliana'nın kök, rozet yapraklar ve çiçeklerine kıyasla, sap ve yaprak yapraklarında önemli derecede daha yüksektir. Enzimlerin bir diğer sınıfi, inorganik kükürtün Cys'e dâhil edilmesinden sorumlu olan O-asetil-L-serin (tiyol) liyazdır ve serbest $\mathrm{H}_{2} \mathrm{~S}$ sadece küçük bir reaksiyonla ortaya çıkmaktadır (Jin ve Pei, 2015).

Hidrojen sülfür birikimi, bitkilerin stres koşullarına toleransı ile yakından ilişkilidir. Ayrıca $\mathrm{NaHS}$ ve morfolin-4-ivum 4 metoksifenil (morfolini) fosfinoditiyaat) (GYY4137) gibi donörlerden salınan dişarıdan uygulanan $\mathrm{H}_{2} \mathrm{~S}$, tohum çimlenmesi, organogenesis ve büyüme, yaşlanmanın düzenlenmesi, tuz stresi, kuraklık, ağır metal stresi, sıcak ve soğuk toleransı gibi stres koşullarında belirgin pozitif etkilere sahip olduğu gözlenmiştir. Bitkilerin ağır metal streslerine özellikle en şiddetlisi olan $\mathrm{Cd}$ stresine hılı $\mathrm{H}_{2} \mathrm{~S}$ üretimi ile tepki vermektedir. Çeltikte $\mathrm{Cd}$ stresi altında $\mathrm{H}_{2} \mathrm{~S}$ üretiminin arttığ1 gözlenmiştir (Mostofa ve ark., 2015).

Tuz stresi de hızlı bir şekilde $\mathrm{H}_{2} \mathrm{~S}$ üretimini tetiklemektedir. Yoncada $\mathrm{NaCl}$ stresinin, $\mathrm{H}_{2} \mathrm{~S}$ içeriğinin normal koşullara göre 2 kattan daha fazla artışına neden olduğu ortaya çıkmıştır (Lai ve ark., 2014). Kuraklık stresi ise en şiddetli abiyotik streslerden birisi olup, Arabidopsis fidelerinde $\mathrm{H}_{2} \mathrm{~S}$ içeriğinin artmasına neden olmuştur (Jin ve ark., 2011). Shi ve ark. (2013) soğuk stresi koşullarında $\left(+4{ }^{\circ} \mathrm{C}\right)$ bermuda çimi fidelerinde $\mathrm{H}_{2} \mathrm{~S}$ seviyesinin arttığ1 bulunmuştur. Chen ve ark. (2016) $35{ }^{\circ} \mathrm{C}$ yüksek sıcaklık uygulamasının tütünde $\mathrm{H}_{2} \mathrm{~S}$ üretimi artışı ile L-sistein desülfhidraz (LCD), aktivitesini artırdığını ve yüksek sıcaklık nedeniyle $\operatorname{artan} \mathrm{H}_{2} \mathrm{~S}$ 'ün jasmonik asit birikimine neden olduğunu ve bunu takiben nikotin sentezini teşvik ettiğini ortaya koymuşlardır. $\mathrm{Bu}$ durum yüksek sicaklık stresine maruz kalan tütün bitkilerinde $\mathrm{H}_{2} \mathrm{~S}$ ve nikotin biyosentezi arasındaki ilişkiyi göstermektedir. Li ve ark. (2016b) UV-B radyasyonunun arpa fidelerinin yapraklarında $\mathrm{H}_{2} \mathrm{~S}$ üretimine neden olduğunu, 12 saatlik maruz kalma sonucunda en üst düzeye ulaştığını vurgulamışlardır. Cheng ve ark. (2013) hipoksi koşullarda bezelye fidelerinde $\mathrm{H}_{2} \mathrm{~S}$ biyosentez sisteminin L-sistein desülfhidraz, D-sistein desülfidraz, O-asetilserin (tiyol) liyaz, sistein sentaz aktif hale geldiğini vurgulamışlardır.

\section{Sonuçlar}

Son yıllarda yapılan çalışmalar, $\mathrm{H}_{2} \mathrm{~S}$ 'ün yüksek konsantrasyonlarda fitotoksik olması yanında çeşitli metobolik ve fizyolojik olaylar sonucunda içsel olarak üretildiğini göstermektedir. Bitki içerisinde üretilen bu $\mathrm{H}_{2} \mathrm{~S}$ 'ün fizyolojik olarak birçok olayda rol oynadığı görülmektedir. $\mathrm{H}_{2} \mathrm{~S}$ varlığının farklı stres durumlarında tetiklenebileceği veya üretilen $\mathrm{H}_{2} \mathrm{~S}$ 'ün stres durumlarında sinyal rolü üstlendiği saptanmıștır. Buna en güzel örnek olarak düşük konsantrasyonlarda patojenlere, kuraklık, sicaklık stresi, ağır metal stresi ve ozmotik stres gibi çeşitli stres koșullarına karşı bitkilerin toleransını artırması gösterilebilir. Özellikle stomalar üzerinde ABA kaynaklı bitki su dengesinin sağlanması için kapanma sinyalinin üretilmesine katkıda bulunması kuraklığa dayanıklılık yönünden değerlendirilmesi gereken önemli bir konudur. Enerji odaklı jeotermal sistemlerden açığa çıkan $\mathrm{H}_{2} \mathrm{~S}$ 'ün yoğun olarak gündeme geldiği alanlarda ve bitki topluluklarında, bitki fizyolojisi ve strese tolerans açısından da değerlendirmelerin yapılması gerektiği kanısına varılmıştır.

\section{Kaynaklar}

Anonymous, 2013. Climate Change 2013: The Physical Science Basis. Intergovernmental Panel on Climate Change, Cambridge, UK.

Becklin, K.M., Anderson, J.T., Gerhart, L.M., Wadgymar, S.M., Wessinger, C.A., Ward, J.K., 2016. Examining plant physiological responses to climate change through an evolutionary lens. Plant Physiology, 172(2): 635-649.

Bharwana, S.A., Ali, S., Farooq, M.A., Ali, B., Iqbal, N., Abbas, F., Ahmad, M.S.A., 2014. Hydrogen sulfide ameliorates lead-induced morphological, photosynthetic, oxidative damages and biochemical changes in cotton. Environmental Science and Pollution Research, 21(1): 717-731.

Calderwood, A., Kopriva, S., 2014. Hydrogen sulfide in plants: From dissipation of excess sulfur to signaling molecule. Nitric Oxide, 41: 72-78.

Chen, X., Chen, Q., Zhang, X., Li, R., Jia, Y., Ef, A.A., Jia, A., Hu, L., Hu, X., 2016. Hydrogen sulfide mediates nicotine biosynthesis in tobacco (Nicotiana tabacum) under high temperature conditions. Plant Physiology and Biochemistry, 104: 174-179.

Cheng, W., Zhang, L., Jiao, C.J., Su, M., Yang, T., Zhou, L.N., Peng, R., Wang, R., Wang, C., 2013. Hydrogen sulfide alleviates hypoxia-induced root tip death in Pisum sativum. Plant Physiology and Biochemistry, 70: 278-286. 
Çengel, Y., 2015. Jeotermal enerjinin çevre ve sağlık etkileri. Adnan Menderes Üniversitesi Rektörlüğü Jeotermal Enerji Araştırma ve Uygulama Merkezi Yayınlar1, 2: 1-10.

Da-Silva, C.J., Modolo, L.V., 2018. Hydrogen sulfide: a new endogenous player in an old mechanism of plant tolerance to high salinity. Acta Botanica Brasilica, 32(1): 150-160.

De Kok, L.J., Bosma, W., Maas, F.M., Kuiper, P.J.C., 1985 The effect of short-term $\mathrm{H}_{2} \mathrm{~S}$ fumigation on water-soluble sulphydryl and glutathione levels in spinach. Plant, Cell and Environment, 8: 189-194.

Hällgren, J.E., Fredriksson, S.A., 1982. Emission of hydrogen sulfide from sulfur dioxide-fumigated pine trees. Plant Physiology, 70(2): 456-459.

Jin, Z., Pei, Y., 2015. Physiological implications of hydrogen sulfide in plants: Pleasant exploration behind its unpleasant odour. Oxidative Medicine and Cellular Longevity, 397502, doi:10.1155/2015/ 397502.

Jin, Z., Shen, J., Qiao, Z., Yang, G., Wang, R., Pei, Y., 2011. Hydrogen sulfide improves drought resistance in Arabidopsis thaliana. Biochemical and Biophysical Research Communications, 414(3): 481486.

Lai, D., Mao, Y., Zhou, H., Li, F., Wu, M., Zhang, J., He, Z., Cui, W., Xie, Y., 2014. Endogenous hydrogen sulfide enhances salt tolerance by coupling the reestablishment of redox homeostasis and preventing salt-induced $\mathrm{K}+$ loss in seedlings of Medicago sativa. Plant Science, 225: 117-129.

Li, Z.G., Min, X., Zhou, Z.H., 2016a. Hydrogen sulfide: a signal molecule in plant cross-adaptation. Frontiers in Plant Science, 7: 1621.

Li, Q., Wang, Z., Zhao, Y., Zhang, X.C., Zhang, S.J., Bo, LT., Wang, Y., Ding, Y.F., An, L.Z., 2016 b. Putrescine protects hulless barley from damage due toUV-B stress via $\mathrm{H}_{2} \mathrm{~S}$-and $\mathrm{H}_{2} \mathrm{O}_{2}$-mediated signaling pathways. Plant Cell Reports, 35(5): 1155-1168.

Lisjak, M., Teklic, T., Wilson, I.D., Whiteman, M., Hancock, J.T., 2013. Hydrogene sulfide: environmental factor or signaling molecule? Plant Cell and Environment, 36(9): 1607-1616.

Mostofa, M.G., Rahman, A., Ansary, M.M.U., Watanabe, A., Fujita, M., Tran, L.P., 2015.
Hydrogen sulfide modulates cadmium-induced physiological and biochemical responses to alleviate cadmium toxicity in rice. Scientific Reports, 5: 14078.

Mutia, T., Jónsdóttir, I.S., Friğriksson, Ş., 2013. Air quality and plant eco-physiological responses around geothermal power plants in Iceland and Kenya. Geotermal Research Council Transactions, 37: 805810.

Pandey, S., 2014. Hydrogen sulfide: A new node in the abscisic acid-dependent guard cell signaling network? Plant Physiology, 166: 1680-1681.

Sekiya J., Schmidt A., Rennenberg H., Wilson L.G., Filner P., 1982. Hydro-gen sulfide emission by cucumber leaves in response to sulfate in light anddark. Phytochemistry, 21: 2173-2178.

Shi, H., Ye, T., Chan, Z., 2013. Exogenous application of hydrogen sulfide donor sodium hydrosulfide enhanced multiple abiotic stress tolerance in bermudagrass (Cynodon dactylon (L). Pers.). Plant Physiology and Biochemistry, 71: 226-234.

Wang, R., 2012. Physiological implications of hydrogen sulfide: A whiff exploration that blossomed. Physiological Reviews, 92(2): 791-896.

Zhang, H., Hu, L.Y., Hu, K.D., He, Y.D., Wang, S.H., Luo, J.P., 2008. Hydrogen sulfide promotes wheat seed germination and alleviates oxidative damage against copper stress. Journal of Integrative Plant Biology, 50(12): 1518-1529.

Zhang, H., Tan, Z.Q., Hu, L.Y., Wang, S.H., Luo, J.P., Jones, R.L., 2010. Hydrogen sulfide alleviates aluminum toxicity in germinating wheat seedlings. Journal of Integrative Plant Biology, 52(6): 556567.

Zhang, H., Tang, J., Liu, X.P., Wang, Y., Yu, W., Peng, W.Y., Fang, F., Ma, D.F., Wei, Z.J., Hu, L.Y., 2009a. Hydrogen sulfide promotes root organogenesis in Ipomoea batatas, Salix matsudana and Glycine max. Journal of Integrative Plant Biology, 51(12): 1084-1092.

Zhang, H., Ye, Y.K., Wang, S.H., Luo, J., Tang, J., Ma, D.F., 2009b. Hydrogen sulphide counteracts chlorophyll loss in sweet potato seedling leaves and alleviates oxidative damage against osmotic stress. Plant Growth Regulation, 58(3): 243-250. 